\title{
Manipulador: uma relação entre espaço, luz e objeto
}

\author{
Handler: a relation between \\ space, light and object
}

Rafael Cardoso Jacinto ${ }^{1}$

Rebeca Lenize Stumm ${ }^{2}$ 


\section{Resumo}

Este trabalho tem como objetivo discutir uma poética baseada na luz como materialidade a ser manipulada pelo artista, para compor espaços de luz e de visualidades, em ambientes expositivos. Por meio de objetos em situações de propagação da luz, a discussão transita não só por questões que identificam o potencial da luz a fim de modificar o ambiente, como também propõem o artista como um manipulador de objetos/ luz. Além disso, a pesquisa se baseia no levantamento de discussões acerca de trabalhos em que a luz protagoniza - acontecimento artístico e propõe também ampliação de perspectivas da ação do artista como um manipulador, envolvido em um processo poético, no contexto da arte contemporânea.

Palavras-chaves: Arte e visualidade; luz; iluminador; manipulador de luz

\section{Abstract}

This paper aims to discuss a poetic based on light as materiality to be manipulated by the artist to compose spaces of light and visualities in expositive environments. By means of objects in situations of light propagation, the discussion approaches not only the issues that identify the potential of light to modify the environment, but also proposes the undersatanding of the artist as a handler of objects and/or light. Besides, the research the baseds on rising discussions about works in which the light the artistic's event as well as proposes the ampliation of perspectives of the artist's action as a handler, involved in a poetic process, in the contemporary art context.

Keywords: Art and visuality; light; illuminator; light handler

E-ISSN: 2358.6958

\footnotetext{
${ }_{1}^{1}$ Professor Mestre substituto na Universidade Federal de Santa Maria (UFSM) - cardosojacinto@yahoo.com.br

2 Profa. Dra. No Curso de Artes Visuais, graduação e pós-graduação, na Universidade Federal de Santa Maria (IFSM) - rzstumm@gmail.com
} 
A linguagem visual é uma das primeiras possibilidades de percepção e comunicação com o mundo desde o princípio da vida do homem, quando se depara com tantas cores, formas e volumes diferentes após o nascimento. Tudo isso, porém, não poderia ser revelado se não existisse a presença da luz. Se estivéssemos imersos à ausência total de uma fonte luminosa, seja ela natural ou artificial, não poderíamos captar as formas e cores através do sentido da visão, somente a uniformidade estabelecida pela ausência de uma fonte luminosa, o escuro. É a luz que nos revela, visualmente, todas as formas e cores existentes no mundo material.

A luz, como forma necessária da percepção visual, faz-se presente no mundo desde a era Primitiva, através do sol ou do fogo que, por sua vez, passou a ser manipulado. Historicamente, no teatro não é diferente, pois desde o princípio de suas manifestações, na Grécia Antiga, dependia-se de uma fonte de luz, para tornar visíveis as encenações que aconteciam ao ar livre, nesse caso, sob atuação natural do sol, que iluminava de forma espontânea e incontrolável, causando efeitos de sombras, translucidez e brilho (em maior ou menor intensidade), que variavam conforme sua posição.

Segundo Camargo (2012), quando o teatro sai da rua e passa a ser encenado em edifícios arquitetônicos, onde a luz solar não era suficiente, há uma necessidade de criar formas artificiais de iluminação e, durante dez séculos, foram utilizados - cronologicamente - os recursos de tochas, velas, querosene e gás, como combustíveis de fonte emissora de luz. Então, após o surgimento da luz elétrica, no século XX, até os dias atuais, na era digital, inúmeras ferramentas e dispositivos de iluminação são fabricados. Aqui ocorre um marco de mudança, outra linguagem passa a operar e esta se encontra entre a arte da cena e a da visualidade, a luz como algo que não só ilumina, mas que causa efeitos, amplifica, esconde, muda o que está posto. Ainda como iluminação teatral, começa a ser pensada como arte e não somente como um recurso que torne visível os atores na cena. Surge a necessidade de se pensar esteticamente a luz, permitindo a singularidade e subjetividade na maneira de iluminar, possibilitando trabalhar sombras, linhas, cores, formas e volumes, ocultar o desnecessário e realçar nuances, transformando um corpo em cena, construindo atmosferas e percepções visuais não apenas no teatro, como em diversas outras formas de arte.

Nas Artes Visuais, historicamente, a luz envolve a incidência sobre formas e superfícies sendo algo que revela, valoriza, possibilita ver mais da matéria e por essa condição, está associada a elementos visuais como cor, intensidade, textura, proximidade/distancia, etc.

A luz muda a aparência das coisas. Uma paisagem vista num dia ensolarado pode parecer brilhante, cheia de contrastes fortes e tonalidades diferentes. Porém, vista num dia nublado, perde estas características, tornando-se monótona e sombria. O mesmo se dá com a luz artificial nos ambientes internos e externos. Conforme o tipo de lâmpada, posição da luminária e quantidade de luz, o ambiente torna-se frio, quente, aconchegante ou impessoal. Além de modificar a aparência física das coisas e dos ambientes que ilumina, a luz tem também o poder de agir sobre as pessoas, alterando seu estado de espírito, seu humor, através das impressões psicológicas que causa. (Camargo, 2000, p.12). 
Entendo que o artista responsável pela criação da luz de um acontecimento artístico precisa conhecer dois aspectos principais que compõem a linguagem da iluminação: a técnica - materiais, ferramentas e conhecimentos técnicos - e o artístico - inter-relação entre a materialidade, os efeitos e as reflexões sobre esta visualidade. Com isso penso que, tecnicamente, o iluminador precisa, antes de tudo, buscar um domínio de conhecimento das diferentes ferramentas emissoras de luz disponíveis no mercado (refletores e projetores), entender suas particularidades, seus princípios elétricos e mecânicos de funcionalidade e aplicação, conhecer os distintos fachos de luz que cada ferramenta projeta, a fim de ser capaz de escolher a ferramenta certa para um efeito desejado, ou mesmo o inesperado. Além disso, é importante que o iluminador atente às possibilidades de utilização de fontes e ferramentas não convencionais.

Cabe ao iluminador dialogar com diversas áreas que de alguma forma se relacionam com o fenômeno da luz, como, por exemplo, teatro, física (óptica), teoria das cores, fotografia, história da arte, biológicas (estudos dos órgãos responsáveis pela visão) etc. Acredito, portanto, que teoria, prática e técnica compreendem um processo cíclico que lapida o artista, assim como o cientista. (Dultra, 2012, p. 69).

Considero ser de fundamental importância que o iluminador tenha um entendimento sobre eletricidade (como ligar cabos, conexões, grandezas elétricas) responsabilidade com a segurança do que está sendo operado, pois esses aspectos estão diretamente presentes num projeto de luz quando, de fato, executado. Destaco também que se faz importante conhecer os fenômenos da física que estudam os conceitos básicos em eletrotécnica, a fim de compreender essa força chamada eletricidade e os efeitos de refração na física. Força essa que não vemos, nem ouvimos, não tem cheiro, forma e cor, atravessa ocultamente um condutor de eletricidade e somente se torna perceptível aos nossos sentidos quando se transforma em algum tipo de trabalho (nesse caso, em energia luminosa).

No entanto, a arte sempre esteve - e estará - atrelada a uma técnica, e o artista cerca-se de todos os possíveis instrumentos que recriam luz, dando-lhe suporte para colocar em prática suas pesquisas.

Na pintura, o artista utiliza pincéis, tintas, solventes, vernizes, palhetas etc. sobre um suporte qualquer. Já na iluminação, os suportes são os próprios palcos e os elementos que compõem as cenas. Os pincéis são os instrumentos; as tintas, as suas luzes colorizadas através de filtros; seus brilhos, suas intensidades, cujo controle geralmente é feito nas mesas (consoles) de iluminação; suas sombras nos cenários, nos elementos, nos atores e tudo o mais que possa ser utilizado para criar efeitos visuais estáticos e dinâmicos com a luz. (Perez, 2017, p 75).

Assim como na comparação de Perez em relacionar o artista da luz e o artista pintor, acredito que da mesma forma que o pintor precisa dominar o conhecimento das técnicas e ferramentas do seu ofício, o artista da luz, por exemplo, precisa observar as criações artísticas dos atores ou performers, pesquisar as linguagens, estilos 
e estéticas que compõem a obra, bem como observar e suscitar conversas com os atores e com o diretor, na tentativa de entender a sensibilidade comum ao grupo e com o intuito de perceber as motivações que os levam a se expressarem frente ao trabalho em questão.

Minha proposta de experimento prático com a luz desenvolvida nessa pesquisa se deu a partir de inquietações que surgiram durante processos de montagem de espetáculos teatrais, nos quais atuei como iluminador (manipulador). Pude perceber que, embora houvesse uma autonomia de criação, a luz estava subjugada a outros elementos, sobretudo ao ator. Assim, eu percebia que a luz não apresentava total independência em sua participação, sendo, no entanto, colaborativa com a totalidade da montagem teatral, a qual envolve diversas outras linguagens na sua composição.

Frente a isso, nas artes visuais e principalmente hoje na Arte Contemporânea, a luz pode atuar protagonizando a ação poética, sendo que a característica de ferramenta colaborativa, na composição da obra, não a faz menos importante, mesmo tendo a possibilidade de ser o próprio acontecimento artístico.

A exemplo disso, alguns artistas que utilizaram da luz, como: Moholy Nagy (1895-1946), Dan Flavin (1933-1996), James Turrell (1943), Anthony McCall (1973), Lúcia Koch (1966), são expoentes da investigação desse tema na arte contemporânea.

A Expansão da arte toma espaço para além das galerias e esses artistas buscam trazer uma nova e importante contribuição para a transformação no modo de fazer e de se pensar arte. A percepção espacial ultrapassa a representação pictórica e alcançam uma relação de modificações que acompanham as transformações acorridas na sociedade.

A arte passa a ser a percepção, não mais o contexto e os objetos presentes. É uma experiência estética, individual e subjetiva, com origem num momento perceptivo, sempre nova em resposta a um determinado lugar e momento. (Barros, 1999, p. 28).

Na década de 1970, um movimento artístico intitulado Light and Space Art, utilizou-se da percepção espacial como principal objeto de seus estudos. Confluindo num intercambio entre arte e ciência. James Turrel e Robert Irwin utilizaram-se da luz como protagonista da percepção espacial nas suas instalações. A arte da percepção coloca o artista intimamente com procedimentos estéticos capazes de ir além do próprio objeto. Segundo Barros (1999, p. 94), "Criar uma atmosfera luminosa, tem por objetivo leva o vedor a fazer indagações pela vivência de algo prazerosamente desorientador, que, tendo origem em uma experiência física, ainda é desconhecido".

\section{O manipulador de luz}

Manipulador. Adj.1. Diz-se daquele ou daquilo que manipula. S. m. 2. Aquele que manipula. 3. Transmissor. [...] Manipular. V.t.d. 1. Preparar com a mão; imprimir forma a (alguma coisa) com a mão. [...] 3. Engendrar, forjar, maquinar. 4. Fazer funcionar; pôr em movimento; acionar. 5. Controlar; dominar. (Ferreira, 2009, p. 64). 
Quando penso na transformação da iluminação ao longo da história, especificamente no campo das artes, percebo que, para a criação de um ambiente/luz utilizando-se de uma fonte natural ou artificial $\neg-$ é necessário que a priori exista a manipulação e/ou organização de objetos. Devido a isso, passo a denominar o sujeito que constrói um ambiente/luz de: manipulador.

Sendo assim, numa instalação artística com luz, por exemplo, quando permitido for que o público não somente observe, mas também interaja com os objetos, seja pela ação direta com as mãos, seja pela presença de seus corpos transformando o ambiente construído, esse mesmo público, que se torna parte do acontecimento como um todo, passa a ser também um manipulador de luz. Acerca disso, Hélio Oiticica (1967) ressalta que "[...] se proponho algo à imaginação alheia, considero que haja, em cada indivíduo, um artista, um poder criador latente".

O iluminador e/ou operador de luz de uma peça teatral se torna um manipulador de objeto/luz desde o momento em que pensa a disposição dos equipamentos no espaço da apresentação, ao pendurar os refletores na vara de luz, durante a afinação, marcação, gravação da mesa, passagem de luz até no momento da operação. 0 manipulador de luz, no acontecimento artístico, é aquele que manipula objetos/luz, a fim de interferir na visualidade e transformar o ambiente, seja na preparação, seja durante o acontecimento.

Podemos perceber, nos trabalhos da artista visual Lucia Koch ${ }^{3}$, por exemplo, que propõem a modificação de um espaço arquitetônico através da interferência da luz, proporcionando ao espectador um "estado alterado" de percepção, que ali existe a manipulação de objetos/luz. Mesmo que a artista se utilize da incidência da luz natural para criar alguns desses ambientes, e que o sol seja o principal responsável por controlar os ambientes criados, é necessária a disposição (manipulação) de objetos que, em algumas de suas obras, são: filtros coloridos e placas de acrílicos com ranhuras dispostos em janelas e aberturas no teto de edificações.

Nesse caso, a artista evidencia em seus trabalhos a opção (pela luz natural) para criar/modificar ambientes em que não se tenha um total controle de operação dessa luz.

$\mathrm{Na}$ atualidade, temos a possibilidade, através de sistemas digitais de projeção de luz, de obter um fino controle na operação da iluminação de um espaço, seja ele uma instalação artística ou um espetáculo teatral. Contudo, paradoxalmente é possível perceber que, ao chegarmos nesse grau de domínio técnico na geração, transformação e controle de luz, ocorrem paralelamente, certas ações artísticas que passam a despreocupar-se com o "controlar" da luz e acabam por refletir sobre o não controle desta.

Outro ponto a se pensar, por meio desse retorno aos objetos simples e primeiros utilizados para controlar a luz, é até que momento o manipulador manipula a luz

\footnotetext{
${ }^{3}$ Lucia Koch nasceu em Porto Alegre e hoje mora e trabalha em São Paulo. É bacharel e mestre em Artes pela UFRGS e doutora em Poéticas Visuais pela USP. Atualmente leciona no curso de Artes Plásticas da FAAP. Já realizou exposições em várias cidades brasileiras e também na Turquia, Alemanha, Áustria, Coreia do Sul, Inglaterra, entre outros países.
} 
ou investiga formas de intervir na sua principal característica de imaterialidade e de fugacidade quando em estado natural.

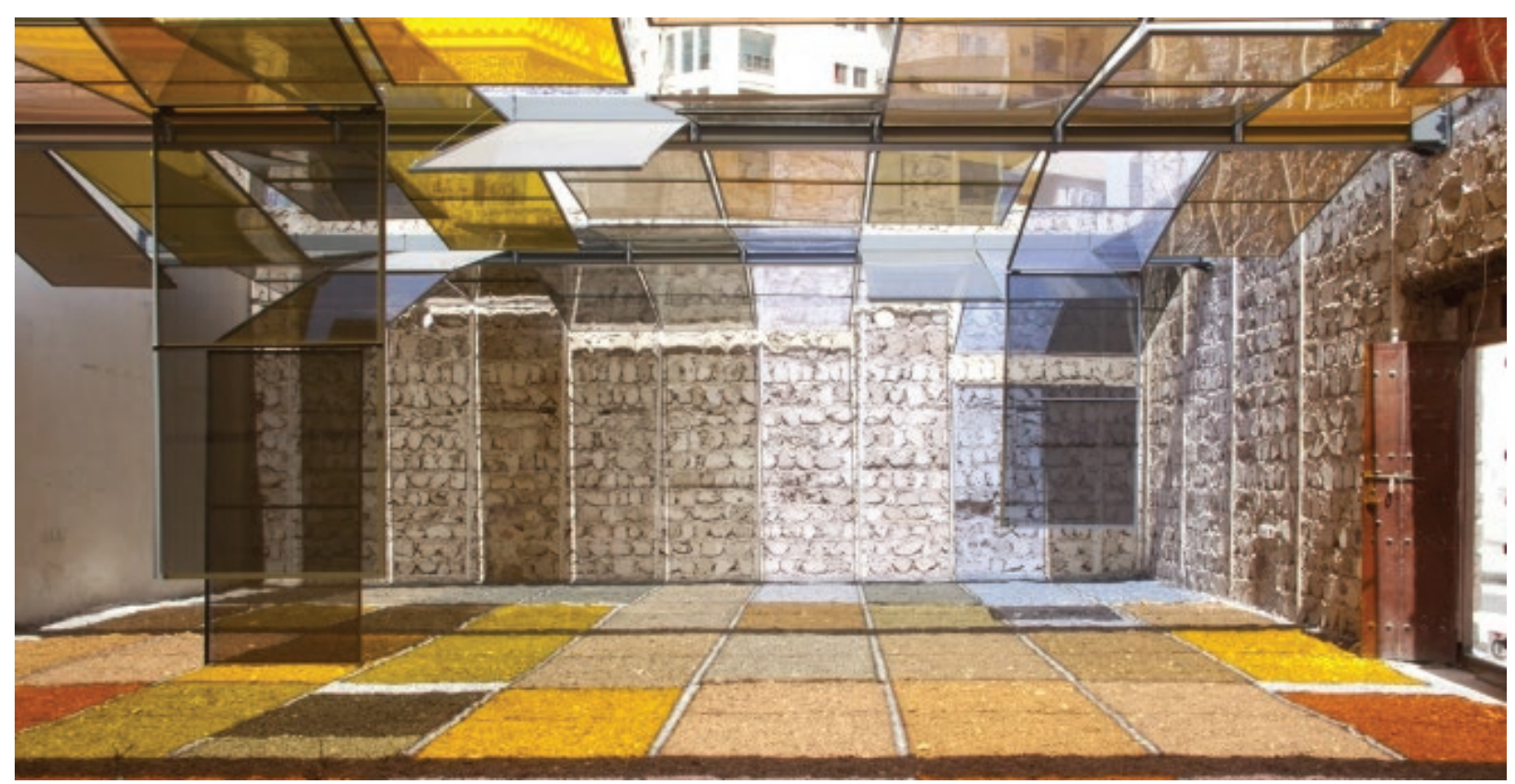

O Gabinete, Lucia Koch - instalação

Fonte: Nara Roesles,1999 - II Bienal do Mercosul. Porto Alegre, Lucia Koch, 1999.

Eduardo Coimbra (RJ), artista brasileiro da atualidade, com formação em engenharia elétrica, aborda a questão da luz em sua pesquisa. Um de seus trabalhos intitulado Nuvem foi exposto na 29ạ Bienal de São Paulo (São Paulo, Brasil, 2010) e na 3a Bienal do Mercosul, em Porto Alegre (Porto Alegre, Brasil, 2001). Segundo Coimbra, o trabalho Nuvem constitui uma escultura de imagem e luz. Para este trabalho o artista usou ferro, impressão em tela translúcida, lâmpadas fluorescentes e espelhos. Os visitantes podiam passear, dar a volta e entre as paredes brilhantes, nas quais Coimbra derrubava o céu para o público explorar. Durante o dia, os painéis espelhados refletiam as luzes brilhantes de um dia ensolarado, enquanto nas últimas horas as caixas eram iluminadas para imitar o mesmo brilho, definido contra a escuridão da noite.

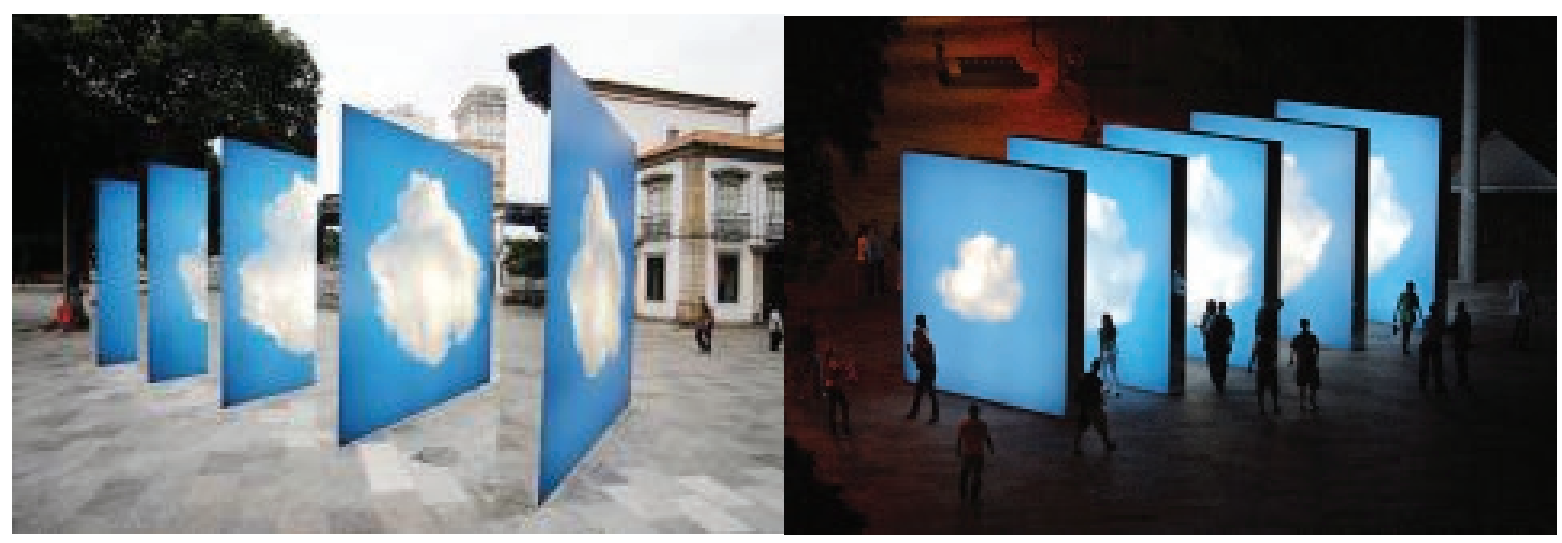

Eduardo Coimbra - Nuvens - Fonte: Wilton Montenegro, 2008. Praça XV de Novembro. Rio de Janeiro- RJ. 
O artista ressalta que a luz aparece em seus trabalhos, no inicio dos anos 1990, em uma fusão dos ofícios de engenheiro eletricista e de artista, nos quais passou a utilizar dispositivos em que a luz funcionava como elemento ativo e, então, nos anos seguintes, começa a utilizar imagens luminosas de céu que, segundo ele, "é a própria imagem da luz. E a imagem de onde vem a luz". Considera que havia um jogo de dupla imaterialidade pois "o azul do Céu não existe, é fruto de refração, desvios e angulações da luz ao atravessar a atmosfera" (Coimbra ,2004 p.116). Dessa forma, por meio de caixas de luz, o artista propõe objetos/luz que possibilitam outras relações com o espaço que os abriga. Estabelece relação com os visitantes do espaço, utiliza-se da luz e também de espelhos para ressaltar a potência da luz. Trabalha dentro de uma categoria de objeto, escultura e instalação no ambiente, tornando-se um manipulador de objetos/luz.

Nesse caso, mesmo que se trata de uma obra fixa, uma instalação, o artista passa a ser um manipulador de luz a partir do momento em que escolhe e organiza os objetos e fontes de luz, a fim de transformar a visualidade do espaço.

A figura do artista e a figura do espectador transitam por entrega à percepção da luz que, nesta pesquisa, manifesta-se também por entrega a ações, muitas vezes, em processos de colaboração, no momento em que se propõe um ambiente constituído por luz, em que outros sujeitos podem se aproximar e manipular, interferindo na luminosidade. Ou seja, com a possibilidade do próprio público interagir, podemos chegar a uma composição visual sempre diferenciada, ofertando um ambiente onde a luz fugaz cria e protagoniza o acontecimento artístico.

Segundo Sandra Rey (2002), no campo das artes, o artista inventa suas próprias regras para que subjetivamente nos mostre sua visão daquilo que o cerca. Para a autora, a pesquisa em arte vai encontrar respaldo teórico na poética, que se propõe como uma ciência e filosofia da criação, levando em conta as condutas que instauram a obra.

Uma obra de arte nasce muito antes de um projeto do que se pretende criar, embora a poética não está ligada ao que se refere ao projeto, nem mesmo à obra "pronta" enquanto produto, nem aos efeitos que a obra rebate no contexto social que a cerca. A poética está diretamente ligada à obra se "fazendo", no momento em que a criação está acontecendo, portanto, essa metodologia só se aplica ao processo prático de uma pesquisa em artes e pelo próprio artista. O percurso de criação de uma obra artística é sinuoso, e a poiética consiste também nos "erros" desse percurso, que levam a uma retomada ou, às vezes, a outras direções que não planejada.

Acredito que faz parte da arte pensar que a pesquisa poética só se torna obra de arte no momento da apresentação junto ao público. Chega um momento da criação em que a obra se instaura, chegando a ter vida própria quando dita os próprios direcionamentos da criação. É nisso que consiste a poiética, na imersão do artista no próprio trabalho e, ao mesmo tempo, um afastamento para ponderar a obra. É no momento de "cegueira" do artista, no qual está tão dentro do processo, que se precisa de um distanciamento e é nesse momento que a obra fala por si. Além disso, no percurso sinuoso do fazer artístico é que se estabelece uma via de duplo sentido entre a imersão e afastamento do artista entre a obra sendo criada.

$\mathrm{Na}$ cultura Árabe, a luz protagoniza um espetáculo histórico/ancestral que 
acontece no interior das residências. O Muxarabi é uma técnica que implica em envolver uma tela em madeira com cavidades em formas geométricas e coloca-las em grandes janelas, as quais impossibilitam a visibilidade de quem está no ponto externo da residência e, ao mesmo tempo, permitem que a luz do sol adentre ao ambiente, difundindo-se nas cavidades e compondo um ambiente de luz e sombra no interior das residências. Como se fosse um espetáculo de luz e formas que vai se modificando conforme a posição e incidência do sol durante a passagem do dia. Nesse espetáculo natural, a luz do sol dirige a composição, da mesma forma que os vitrais coloridos, nas igrejas medievais, colaboravam na composição das cenas dos dramas litúrgicos.

Em geral, a janela é grelhada a fim de operar uma separação entre o interior e o exterior, separação que delimita também a fronteira entre a esfera privada e a pública. Os moradores permanecem invisíveis para a rua, enquanto estes são capazes de observar de casa, sem serem vistos, o que se passa lá fora. A luz penetra no espaço interno através da janela, como que através de um filtro denso. No interior, a tela da janela produz um motivo em reflexo, que se desloca lentamente no ambiente com a luz do dia e sua alteração. (Alloa, 2015, p128).

Nesses casos, há a possibilidade de, além do indivíduo que projetou o espaço, o próprio ocupante da residência passa a ser um manipulador de objeto/luz quando simplesmente transita, se coloca em meio ao espaço constantemente transformado pela ação do sol nos objetos.

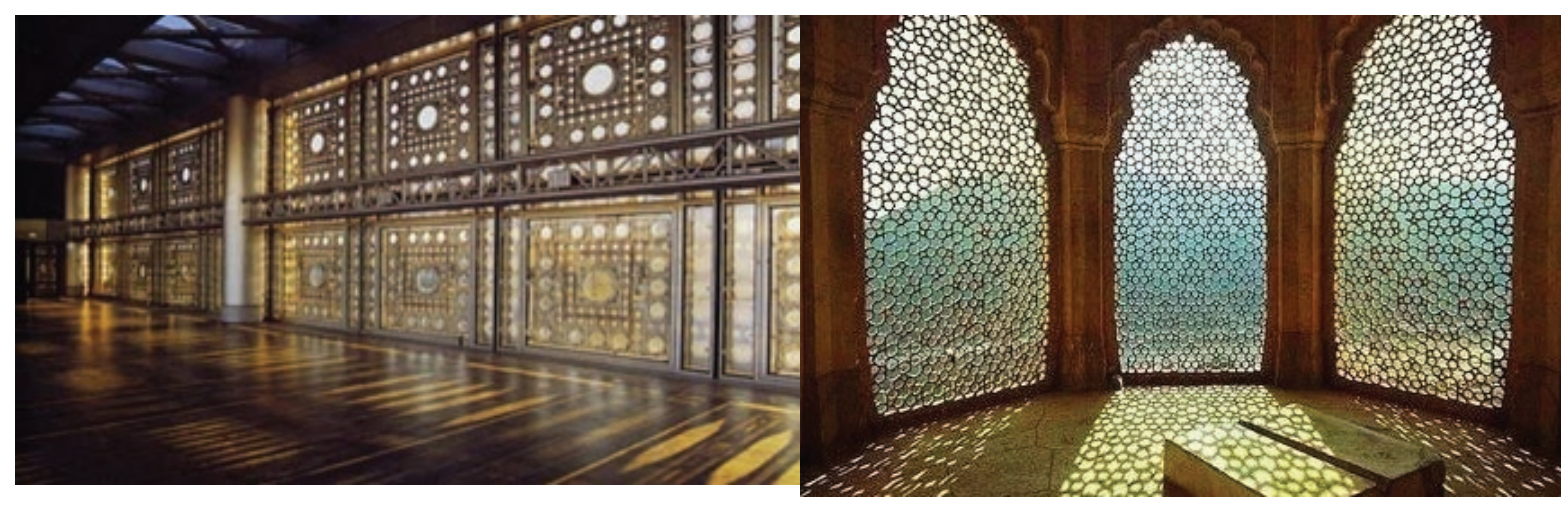

Muxarabe - luz incide modificando os ambientes na passagem do dia Fonte: Catarina Ldebour. Arquitetura Ch.

Outro caso em que me vejo percebendo a luz atuando como modificadora de um ambiente público é quando passo a ser um manipulador de objeto/luz, num universo não de caráter artístico, mas religioso.

Durante os rituais litúrgicos de Umbanda ${ }^{4}$, na qual faço parte desde os meus seis anos de idade, frequentemente, fazemos uso de velas, fogo e projeções de luzes coloridas, que têm por finalidade contribuir física e energeticamente com os trabalhos mediúnicos realizados durante o ritual. Consecutivamente, em um contexto religio-

4 Religião brasileira que sintetiza vários elementos das religiões africanas e cristãs, porém sem ser definida por eles. Formada no início do século XX no sudeste do Brasil por Zélio Fernandino de Moraes a partir da síntese com movimentos religiosos como o Candomblé, o Catolicismo e o Espiritismo. (Cumino, 2019, p. 16) 
so, criar situações de luz, assim como na arte, é algo que nos remete a outros espaços, possibilitando-nos desconhecer, por algum tempo, o ambiente frequentado. Nas artes visuais, meu trabalho interfere no ambiente, ocupando-o por determinado tempo, transformando a forma como vemos o espaço e as materialidades envolvidas. Por vezes, algo nos faz olhar para a luz e imediatamente olhar para a fonte de luz, revelando, causando a ampliação de como vemos esses objetos e espaços. Causando uma experiência que nos envolve como corpo presente naquele espaço.

Durante os rituais de umbanda, nós médiuns, ao construirmos e/ou transformarmos um ambiente, a partir da iluminação, assumimos o papel de um manipulador de objeto/luz.

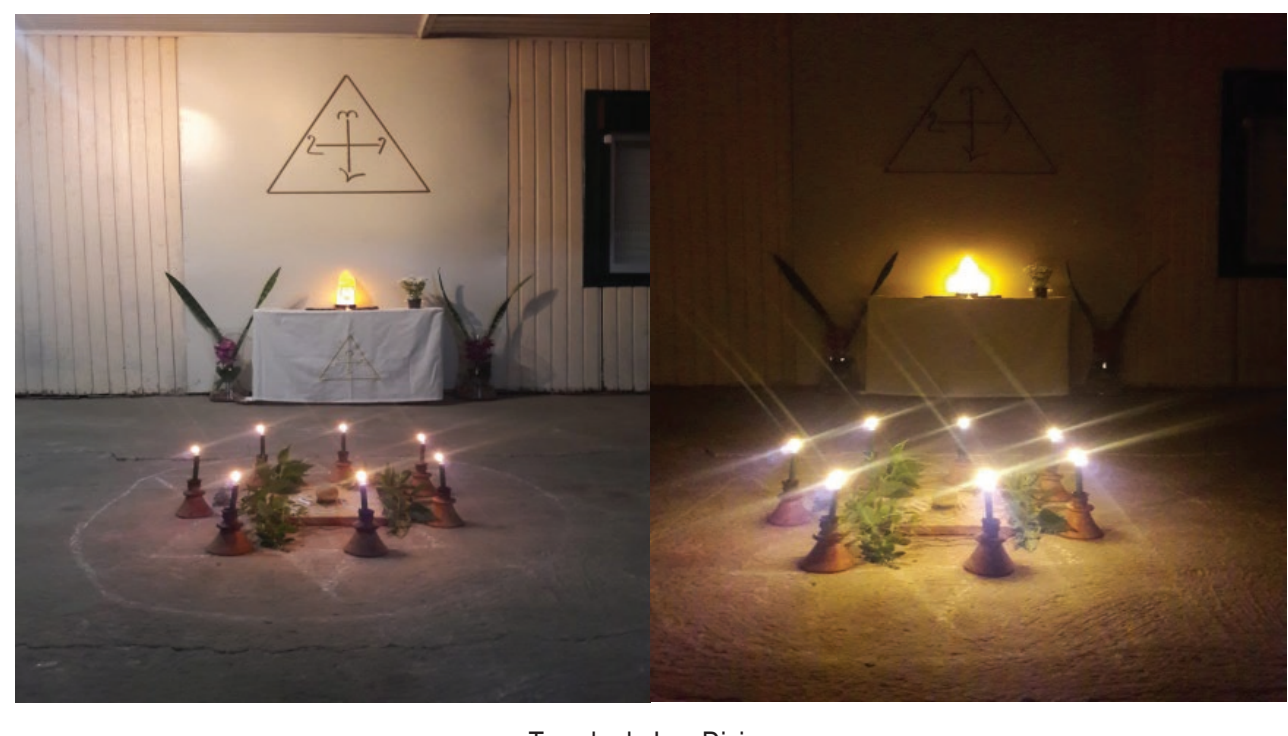

Fonte: Rafael Jacinto. Registro do ritual litúrgico -Templo da luz divina, Santa Maria-RS, 2019.

A "luz" carrega consigo muitos significados, sentidos perceptivos, com a luz do sol que é energia e vitalidade humana; a luz divina que estabelece a comunicação entre os deuses, como na religião; cor; calor; energia; reflexo; sombra nos objetos. Além das experiências sensoriais de profundas explicações, quando falamos em luz, falamos em física, biologia, artes, psicologia, filosofia, etc. Trabalhar com a luz, (independente da linguagem artística), possibilita um ato ilimitado de iluminar, dar a ver nuances. Ultrapassamos o ato de apenas dar a ver e mergulhamos num inesgotável ambiente de possibilidades de criação e percepção.

O ato de ver não é o ato de uma máquina de perceber o real enquanto composto de evidências tautológicas. $O$ ato de dar a ver não é o ato de dar evidências visíveis a pares de olhos que se apoderam unilateralmente do dom "visual". Dar a ver é sempre inquietar o ver, em seu ato, em seu sujeito. Ver é sempre uma operação de sujeito, portanto uma operação fendida, inquieta, agitada, aberta. Todo olho traz consigo sua névoa, além das informações de que poderia num certo momento julgar-se o detentor. (Didi-Hubermam, 1998).

O ponto de partida para este trabalho surgiu da necessidade de buscar uma maneira de se trabalhar artisticamente com a luz onde a mesma protagonize o aconte- 
cimento, explorando os conhecimentos que hoje se tem sobre a luz, como elemento de construção visual no espaço e perceber a sua relação com o observador.

Foi a partir das reflexões acerca dos trabalhos com luz que realizei durante as residências artísticas e durante as concepções e operações da iluminação dos espetáculos teatrais, que surgiu a inquietação por aprofundar as discussões frente à figura do manipulador de luz, que, por sua vez, se diferencia e não se restringe apenas ao oficio do operador de luz de um espetáculo teatral.

$\mathrm{Na}$ condição de manipulador de luz de um acontecimento artístico, o artista encontra-se na situação de sujeito que interfere na visualidade do espaço através da manipulação de objetos/luz, que vai desde a preparação deste espaço artístico até o encontro com o público, que também pode vir a ser um manipulador, assim como o performer o ator e o individuo, que respectivamente transitam na ação performática, na cena teatral e na residência Árabe.

Em novembro de 2017, durante uma residência artística realizada na Cidade de Silveira Martins - RS, concebi o trabalho intitulado "Mesa de manipulação", o qual foi construído a partir de um espelho que capta a projeção da luz de uma ferramenta emissora e reflete para o teto as formas e cores que são criadas na face do espelho, utilizando líquidos e filtros coloridos que, misturados na água, constroem imagens com possibilidades de movimento.

Para a composição da Mesa de manipulação são utilizados: um refletor de luz tipo Plano Convexo, dois espelhos com dimensões $100 \times 50 \mathrm{~cm}$ cada, uma estrutura de madeira de $100 \times 100 \mathrm{~cm}$, plástico transparente, gelatinas de cores variadas, água, sabão liquido, óleo de cozinha e outros pigmentos.

A mesa de manipulação pode ser compreendida como uma forma analógica de manipular e transportar a luz de uma superfície para outra superfície. A ideia parte das apresentações teatrais Gregas que, por volta de 539 a.C, já exploravam as tentativas de manipulação da luz para criarem efeitos de sombras, quando utilizavam placas de material reflexivo e conseguiam interferir na luz captada do sol.

Neste trabalho, especificamente, direciono o foco de atenção para cima, onde o público precisa se colocar corporalmente olhando pra cima, não somente para compor o trabalho no ato da manipulação, enquanto manipulam, mas também, para perceber os efeitos criados, ampliados e transformados dos materiais manipulados, transformando-se em imagem-luz acima de suas cabeças.

A projeção da luz refletida pelo espelho modifica a dimensão dos elementos projetados no teto, que, em movimentos repercutidos pela água, apresentam-se por alguns momentos de forma abstrata. As mãos dos manipuladores, cabelos e outras partes do corpo, quando entram em contato com a luz, acabam fazendo parte da composição projetada tanto no espelho quanto no teto. 

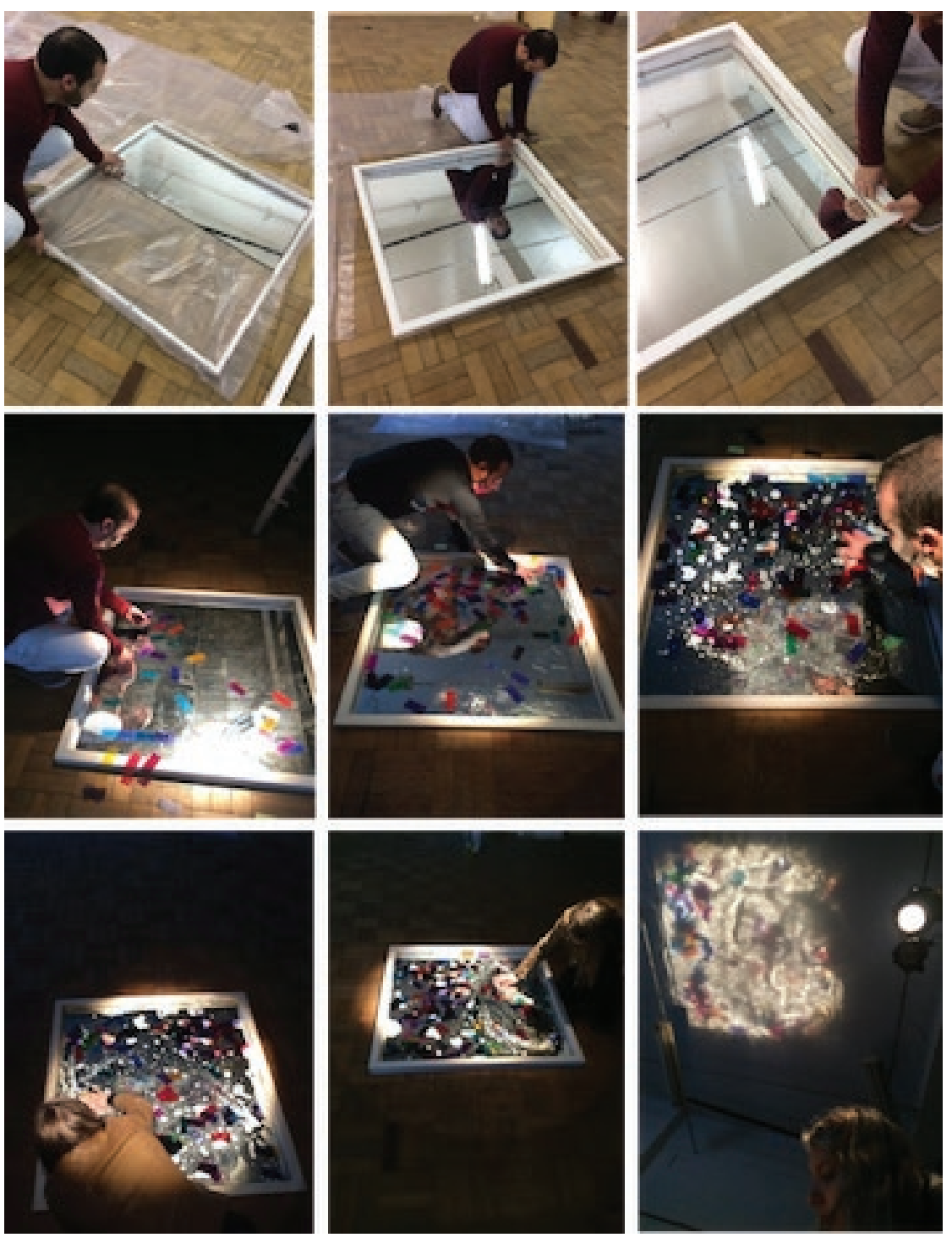

Montagem e manipulação na Mesa de manipulação Fonte: Arquivo pessoal do artista

O que a luz em projeção constrói é uma "janela" que se forma no teto e convida o espectador a se colocar ativo no trabalho desde um momento em que precisa inclinar sua cabeça para trás, a fim de observar o trabalho.

Durante a apresentação desse trabalho, num evento em comemoração aos 25 anos de fundação do Teatro Caixa Preta - UFSM, pude perceber a interação do público modificando os filtros coloridos, alternando cores e formas que preenchiam o teatro. Luz e forma interagiam com o espaço, com a ação e a percepção do público de tal maneira que o trabalho não aconteceria separadamente.

Sobre a projeção, ainda que o espelho, pelo reflexo da luz, "transporte" a imagem para uma superfície outra, existe uma diferença visual entre a imagem criada no espelho e a imagem projetada no teto. Existe uma relação entre quem compõe a obra (nesse caso o público) e os objetos/luz que criam as imagens. A luz, o espaço e os corpos (objetos e humanos) se fundem na composição e no ato presente. Como forma de reflexão sobre o trabalho, observo-o sob a perspectiva de três planos: num plano mais próximo, temos a imagem criada na mesa de espelho vista por quem ma- 
nipula e/ou observa; no segundo plano, a imagem projetada no teto, vista também pelo manipulador ou observador e, por fim, a imagem num plano mais aberto, em que é possível observar as imagens sendo criadas pelo manipulador.
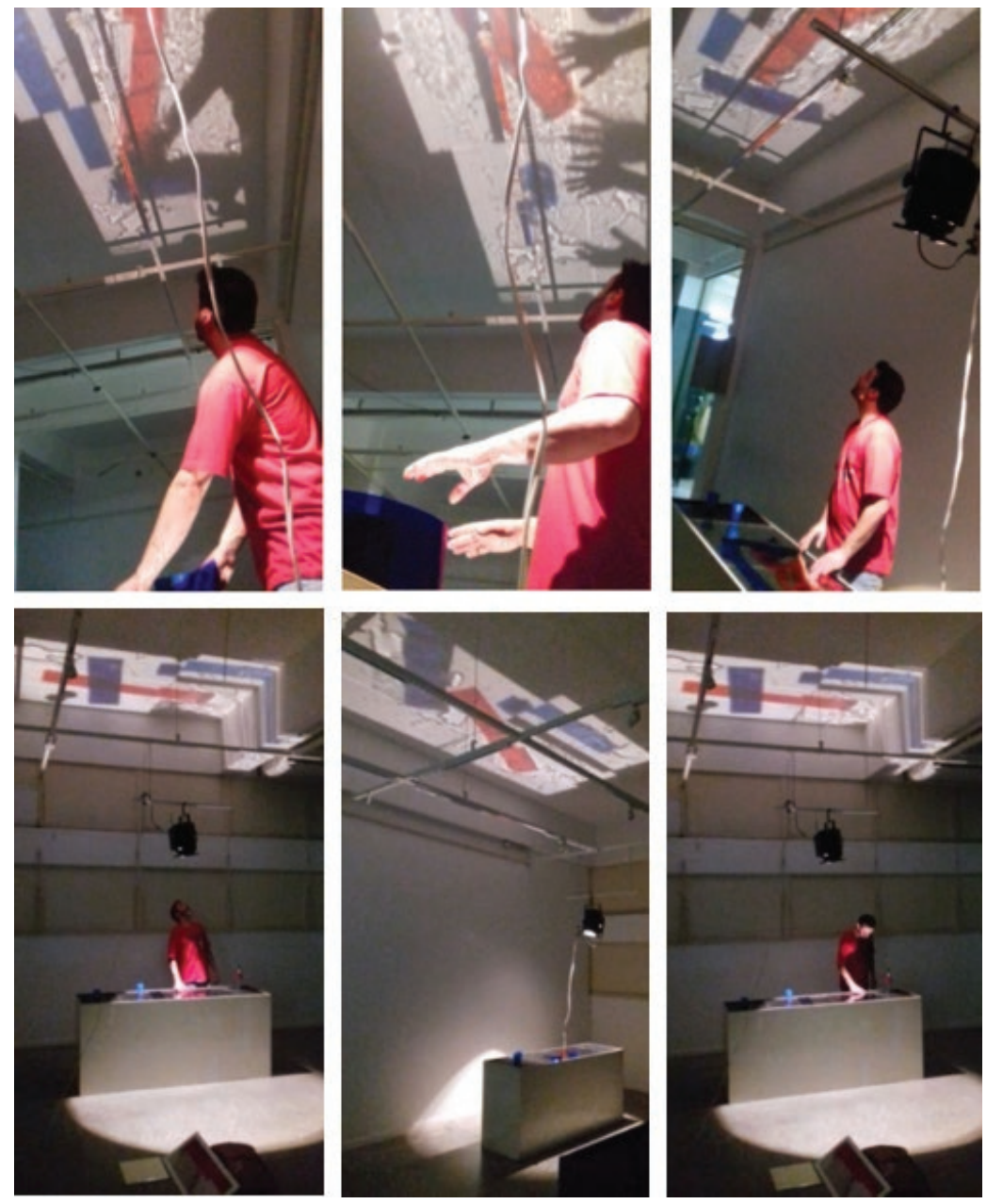

Montagem e manipulação na Mesa de manipulação Fonte: Arquivo pessoal do artista 

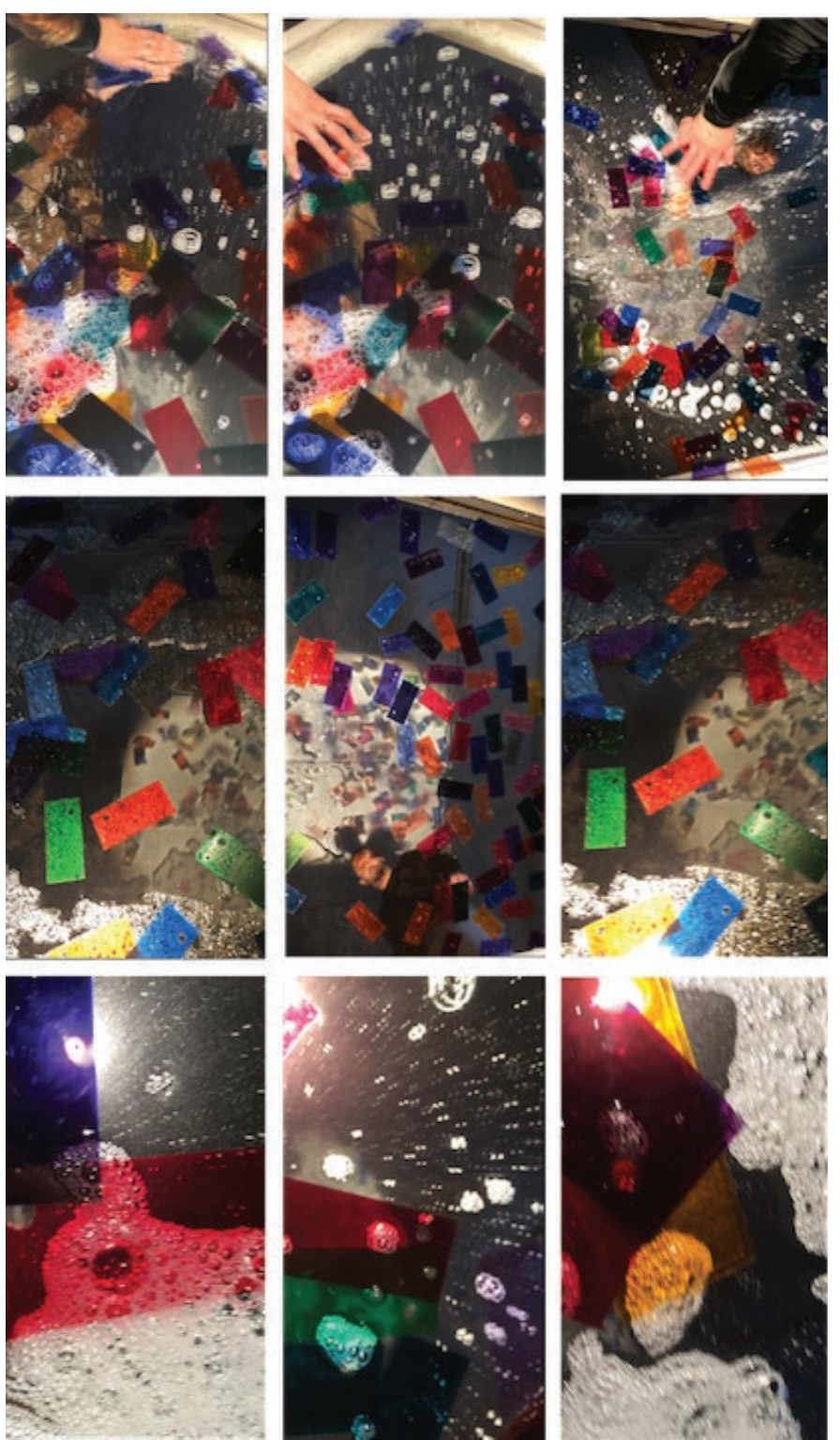

Montagem e manipulação na Mesa de manipulação Fonte: Arquivo pessoal do artista 

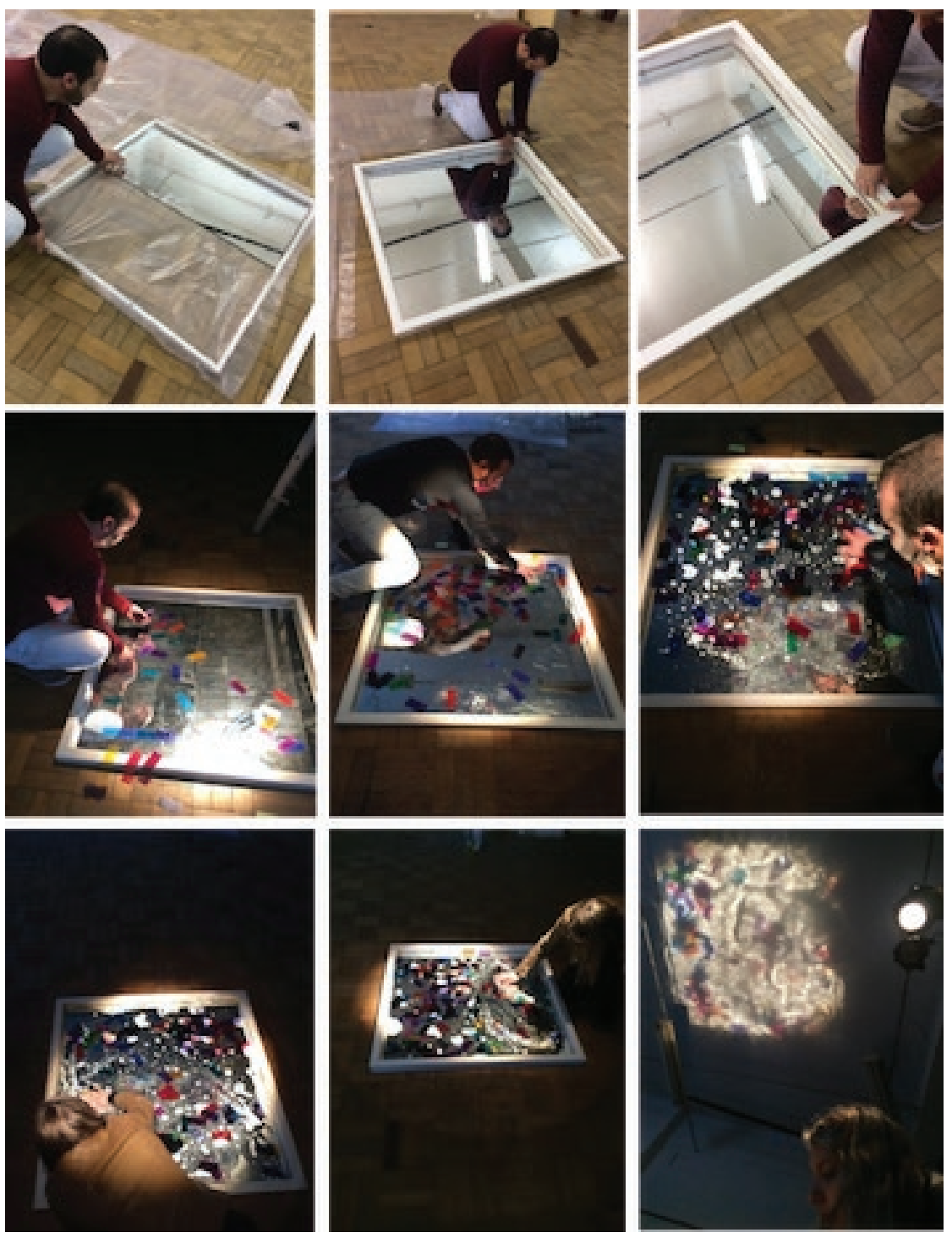

Montagem e manipulação na Mesa de manipulação

Fonte: Arquivo pessoal do artista

\section{Considerações Finais}

$\mathrm{Na}$ atualidade, certas ações ou acontecimentos como a incidência de luz em janelas planejadas pela arquitetura (como é o caso dos muxarabes), ou a luz como elemento litúrgico-estético-religioso em templos de umbanda, que talvez antes pudessem estar no terreno da experimentação fugaz, hoje podem ser vistos inseridos ou deslocados de diferentes formas para o contexto de atuação do artista na Arte Contemporânea. É nesse espaço que percebemos uma abertura de profusão de estratégias de atuação do artista da luz e linguagens em que a iluminação se faz presente, assim como diferentes linguagens e materiais são resgatados e ganham espaço de reflexão e ressignificação enquanto arte.

Segundo Archer (2001, p. 10), "quem examinar a arte dos dias atuais será confrontado com uma desconcertante profusão de estilos, formas, práticas e programas" sendo assim, enfatiza-se que os artistas se apropriam de distintos processos e ele- 
mentos, próprios da arte ou cotidianos, para sua produção, definindo que se torna cada vez mais difícil a certeza de que alguma característica qualifica o que é ou não arte. A luz gerada por uma vela, uma sombra projetada na parede ganham outros sentidos. A possibilidade do fazer do artista e os objetos/luz tornam-se materiais de trabalho que trazem para a arte a instabilidade, o efêmero, os efeitos, a relação com os contextos e o público.

A Arte Contemporânea permeia um cenário de experimentações e permite ao manipulador, buscar na história do teatro, na história da iluminação, objetos e procedimentos que juntos, ganham a construção de um ambiente em transformação junto ao público também participante (manipulador). Assim, novas práticas e proposições artísticas, as quais podem se aproximar, muitas vezes, desse universo cotidiano, sugerem nova perspectiva de atuação ao artista da luz.

\section{Referências}

ALLOA, Emmanuel. Pensar a imagem. Belo Horizonte: Autêntica Editora, 2015.

ARCHER, Michael. Arte Contemporânea: uma história concisa. São Paulo: Martins Fontes, 2001.

BARROS, Anna Maria de carvalho. A arte da Percepção: Um namoro entre a luz e o espaço. São Paulo: Annablume, 1999.

CAMARGO, Roberto G. Conceito de Iluminação Cênica. Rio de Janeiro: Música \& Tecnologia, 2012.

CAMARGO, Roberto G. Função Estética da Luz. São Paulo: Perspectiva, 2012.

COIMBRA, Eduardo. Textos Glória Ferreira, Adolfo Monteijo Navas, Ligia Canongia, João mondé, Eduardo Coimbra: versão para o Inglês, Steve Berg e Paulo Andrade Lemos. Rio de Janeiro: Casa da Palavra, 2004.

CUMINO, Alexandre. História da Umbanda: uma religião/brasileira. São Paulo, Madras, 2019.

DIDI-HUBERMANN, Georges. O que vemos, o que nos olha. São Paulo: Editora 34, 1998.

DULTRA, Pedro. Em Cena O Iluminador. Ipatinga: Música \& Tecnologia, 2012.

FERREIRA, A.B.H. Novo Dicionário Aurélio da Língua Portuguesa. 4.ed. Curitiba: Ed. Positivo:2009

OITICICA. Hélio. Parangolé Coletivo [atribuído]. Manuscrito. 08/07/1967. PHO 0106/67 
PEREZ, Valmir. P415d Desenho de iluminação de palco: pesquisa, criação e execução de projetos. / Valmir Perez. - Campinas, SP: [s.n.], 2007. Orientador: José Eduardo Ribeiro de Paiva. Dissertação (Mestrado Em Artes) - Instituto de Artes, Universidade Estadual de Campinas, 2007.

REY, Sandra. Por uma abordagem metodológica da pesquisa em artes visuais. In BRITES, Blanca; TESSLER. Elida (Org.). O meio como ponto zero: metodologia da pesquisa em artes plásticas. Porto Alegre: E. Universidade/ UFRGS, 2002.p.123-140.

Recebido em: 30/10/2019

Aprovado em: 24/01/2020 